\title{
Uso de estratégias de leitura em tecnologia virtual e tecnologia não virtual: um estudo com alunos do 9o ano do Ensino Fundamental e do 10 ano do Ensino Médio
}

\author{
Use of reading strategies on virtual technology and not virtual technology: a study \\ with the 9th grade of middle school and the 1st year of high school
}

\section{Vera Wannmacher Pereira Thais Vargas dos Santos}

Pontifícia Universidade Católica do Rio Grande do Sul - PUCRS - Porto Alegre - Rio Grande do Sul - Brasil

\begin{abstract}
Resumo: Neste artigo, é relatado estudo que examinou a contribuição de materiais para leitura de crônicas, contos e fábulas, em tecnologia virtual e tecnologia não virtual, destinados a alunos do $9^{\circ}$ ano do Ensino Fundamental e do $1^{\circ}$ ano do Ensino Médio, no que se refere ao uso de estratégias de leitura. Teve como base os estudos psicolinguísticos sobre leitura aplicados ao ensino, com apoio da Computação. Envolveu a produção de módulos com foco em estratégias de leitura, a preparação da equipe, a elaboração e a aplicação desses materiais em oficinas na escola selecionada, a elaboração e a aplicação de pré-teste antes das oficinas e de pós-teste após as oficinas e o tratamento dos dados. Os resultados obtidos indicaram: diferença significativa na comparação pré e pós-teste no uso das estratégias de leitura, considerando escolaridade, gênero textual - com destaque a favor da crônica - e ambiente de aprendizagem; ausência de diferença significativa entre as tecnologias, com tendência favorável à virtual no $1^{\circ}$ ano e à não virtual no $9^{\circ}$ ano; e crescimento aproximado entre os dois anos escolares, com tendência favorável ao $1^{\circ}$ ano.
\end{abstract}

Palavras-chave: Uso de estratégias de leitura. Tecnologia virtual. Tecnologia não virtual. Ensino.

\begin{abstract}
In this article, it is reported a study that examined the contribution of materials for chronicles, short stories and fables reading in virtual technology and not virtual technology, destined to students of 9th grade of middle school and of 1st year of high school, regarding the use of reading strategies. The research had as base the psycholinguistic studies on reading applied to education, with support on computation. Involved the production of modules with focus on reading strategies, the team preparation, the development and application of these materials in workshops in a selected school, the development and application of pre-test before the workshops and of post-test after the workshops, and the data processing. The results achieved indicated: significant difference when comparing pre and post-test in the use of reading strategies, considering education level, textual genre - especially in favor to chronicle and learning environment; no significant difference between the technologies, with favorable trend to virtual technology in the 1st year and to not virtual technology in the 9th grade; and approximate increase between the two education levels, with a favorable tendency to the 1 st year of high school.
\end{abstract}

Keywords: Reading strategies use. Virtual technology. Not virtual technology. Teaching. 


\section{Introdução}

Os resultados obtidos por meio das avaliações oficiais brasileiras, confirmados pelos decorrentes das avaliações desenvolvidas pela Organização para a Cooperação e Desenvolvimento Econômico - OCDE indicam dificuldades dos estudantes de todos os níveis de ensino na compreensão de textos. Essas informações, acompanhadas das manifestações continuadas dos diversos segmentos da sociedade, reforçam o reconhecimento de que o problema existe e tem dimensões graves e complexas.

Pesquisadores de diversas áreas vêm dirigindo seu olhar para o que está a ocorrer. Os linguistas, por sua formação, têm responsabilidades correspondentes, com um lugar especial para os psicolinguistas, tratando-se $\circ$ problema de compreensão leitora e seu ensino.

Nesse entendimento, foi desenvolvido, com apoio do CNPq, da CAPES e da FAPERGS, um projeto de estudos psicolinguísticos aplicados, associando ensino, extensão e pesquisa, com sustentação teórica na Psicolinguística Aplicada e apoio na Computação. Teve, como objetivo, examinar a contribuição de módulos de ensino em tecnologia virtual e tecnologia não virtual, organizados em estratégias de leitura de crônicas, contos e fábulas, para 0 uso desses procedimentos cognitivos por alunos de $9^{\circ}$ ano do Ensino Fundamental e $1^{\circ}$ ano do Ensino Médio, anos escolares que, além de evidenciarem dificuldades de leitura, conforme as provas já referidas, realizam a transição entre esses níveis de escolaridade e fazem projeções para o Ensino Superior.

Para tanto, o trabalho envolveu a preparação da equipe (bolsistas graduandos, bolsistas escolares e bolsistas professores), a produção dos módulos de ensino em tecnologia virtual e tecnologia não virtual, o planejamento e a realização das oficinas, a elaboração e a aplicação dos instrumentos de pesquisa e o tratamento dos dados coletados. Os processos e os produtos científicos, tecnológicos e pedagógicos desse trabalho estão divulgados por meio de um ebook disponível no site da Editora da EDIPUCRS'.
Neste artigo, são expostos sucessivamente componentes do estudo realizado - seus fundamentos e delineamento, os resultados obtidos, as conclusões e as referências.

\section{Fundamentos e delineamento do estudo}

O estudo aqui relatado é sustentado teoricamente na perspectiva de leitura como processo cognitivo.

Nesse entendimento, a leitura ocorre por meio de dois processos básicos (SCLIAR-CABRAL, 2008, 2009) que interagem conforme a situação de leitura o bottom-up e o top-down. O processo bottom-up caracteriza-se como ascendente, fazendo 0 movimento das partes para o todo. Constitui-se numa leitura linear, minuciosa, vagarosa, em que as pistas visuais são predominantemente utilizadas. É um processo de composição, uma vez que as partes gradativamente vão formando o todo. O processo topdown, conforme Goodman (1991) e Smith (2003), caracteriza-se como um movimento não linear que faz uso de informações não visuais - dos conhecimentos prévios, predominantemente. Desse modo, dirige-se da macroestrutura para a microestrutura, da função para a forma, baseando-se na concepção antecipatória da leitura.

No estudo aqui relatado, considera-se que os dois movimentos são utilizados pelo leitor, dependendo da situação que se apresenta durante a leitura, envolvendo o próprio texto, o objetivo da leitura e o leitor (conhecimentos prévios). Nesse sentido, o sucesso do desempenho na compreensão da leitura está na escolha do processo dominante e na interação entre ambos, considerando a situação de leitura, em que variáveis se inter-relacionam e produzem influências.

Esses processos ocorrem por meio de dois grupos básicos de estratégias: cognitivas e metacognitivas (KATO, 1987; KLEIMAN, 1989; LEFFA, 1996). As cognitivas caracterizam-se pelos traços intuitivo e inconsciente, enquanto as metacognitivas caracterizam-se pela consciência, pela

\footnotetext{
${ }^{1}$ http:// ebooks.pucrs.br/edipucrs/projetos/100815-001/
} 
intenção de monitoramento do próprio processo. Constituem-se em exemplos de estratégias cognitivas pressuposições intuitivas do leitor, tais como a de que o texto é, a priori, coerente, a de que determinadas ordenações são impossíveis e a de que a escrita, em nossa cultura, ocorre da esquerda para a direita. Constituem-se em exemplos de estratégias metacognitivas situações de monitoramento do processo pelo leitor com o objetivo de garantir a compreensão, tais como: a definição e o controle do objetivo da leitura, a identificação de segmentos importantes, a distribuição da atenção, a avaliação da qualidade da compreensão e a tomada de medidas corretivas. As estratégias de leitura têm como base os elementos que internamente as constituem e que estão distribuídos nos planos constitutivos da língua fônico, mórfico, sintático, semântico, pragmático e textual (GOMBERT, 1992).

A revisão de literatura sobre o assunto indica a existência de um conjunto de estratégias acionadas durante a leitura. Entre essas, são nomeadas com frequência: skimming, scanning, predição, automonitoramento, autoavaliação, autocorreção, inferência e leitura detalhada. De modo a dar continuidade a trabalhos anteriores, foram eleitas, para o estudo aqui relatado, como estratégias de leitura para produção, aplicação e investigação das atividades pedagógicas, a de predição, a de scanning e a de leitura detalhada.

O significado da estratégia de predição está no próprio radical da palavra, permitindo associação a predizer. Possibilita vincular também significativamente a previsão, assim como a antecipação e a adivinhação. Em relação a esta última nomeação, há que explicitar que não se trata de um procedimento impulsivo e aleatório. Consiste num procedimento em que o leitor, com base nas pistas linguísticas e nos seus conhecimentos prévios, faz importantes inferências para a adivinhação. Daí a denominação de guessing game (GOODMAN, 1967).

A seleção das pistas está apoiada no objetivo do leitor, isto é, do que ele deseja antecipar, nas características do texto, isto é, na natureza dos elementos linguísticos que o autor disponibiliza, e nos conhecimentos prévios de que o leitor dispõe para sua busca. Cabe ressaltar que num poema, por exemplo, a predição de uma palavra pode estar apoiada em uma rima anterior, assim como na morfologia de uma palavra ou na estrutura de um verso. Do mesmo modo, a predição de um fato pode estar vinculada à sequência de fatos antecedentes, assim como a predição de uma palavra pode estar ligada ao campo semântico do qual faz parte.

É importante registrar também que a estratégia de predição tem em si um processo inferencial e apoio em outras estratégias de grande importância para o seu êxito - o automonitoramento, a autoavaliação e a autocorreção (PEREIRA e PICCINI, 2006). Constituem-se esses componentes como condições para uma predição eficiente, cabendo ao leitor estar consciente de sua importância e da necessária interação entre elas.

A estratégia de scanning consiste num procedimento cognitivo importante para a leitura, contribuindo para a resolução de problemas durante sua realização. Com origem em scan, pode ser compreendida como exame, sondagem, exploração.

Caracteriza-se fundamentalmente como busca de uma informação específica no texto em diferentes situações. O leitor pode precisar retomar algo já lido e perdido, por problemas de atenção ou memória, como, por exemplo, nome da rua em que ocorreu determinado fato num conto. É possível também que tenha informação parcial e precise totalizá-la, como, por exemplo, as advertências em relação a um medicamento numa bula. Do mesmo modo é possível que não tenha compreendido algo e precise retomar, por exemplo, o significado de uma palavra desconhecida num artigo científico. É ainda possível que não tenha considerado importante a informação, como, por exemplo, quantas vezes uma palavra se repete no texto. Também é possível que o leitor não tenha lido o texto e queira identificar apenas uma informação ali provavelmente disponível, como a data de uma determinada notícia.

Desse modo, o scanning está vinculado a um objetivo específico claramente estabelecido pelo leitor, seja de obtenção de informação, seja de 
aprofundamento de informação parcialmente já obtida, seja de busca de melhor entendimento, sempre em direção à compreensão. Cabe registrar que, para seu uso, o leitor necessita de conhecimentos prévios como apoio, ou sobre o conteúdo ou sobre a natureza do texto.

A estratégia de leitura detalhada, como seu nome sugere, supõe procedimentos minuciosos, cuidadosos por parte do leitor. Conta, para isso, com movimentos lineares de observação de cada sinal linguístico. Insere-se, desse modo, no processamento cognitivo bottom-up, de natureza ascendente, das unidades menores para as maiores.

O uso dessa estratégia está vinculado ao objetivo da leitura, aos conhecimentos prévios do leitor e às características do texto. Quanto ao objetivo de leitura, o leitor poderá preferi-la caso precise posteriormente de todas as informações constitutivas do texto, como para realização de uma prova, elaboração de um resumo, reprodução oral... Em relação aos conhecimentos prévios, caso o leitor não os possua suficientemente, terá de se apoiar com muita atenção em cada pista linguística. No que se refere à natureza do material de leitura, o leitor deve se ajustar ao seu funcionamento, o que indica a necessidade de leitura cuidadosa para situações como léxico pouco conhecido, sintaxe com frases longas e complexas, estruturas textuais com exigência cognitiva alta.

Considerando esse conjunto de concepções, cabe assumir o ponto de vista de que o processo cognitivo de compreensão da leitura (PEREIRA, 2008) se realiza em rede, com os necessários ajustamentos, do que decorre sua natureza de jogo e consequentemente de risco, que exige da parte do leitor o manejo de processos ascendentes e descendentes e de estratégias cognitivas e metacognitivas de leitura (KLEIMAN, 1989).

Esse conjunto de fundamentos integra o processamento da leitura, cabendo considerá-los como base tanto para o suporte virtual como para o não virtual, especialmente quando se desejam ver as aproximações e os afastamentos, como é o caso do estudo aqui relatado. A opção por esse caminho está apresentada na continuidade deste texto.

Com frequência há, na família, na escola, na sociedade em geral, a convicção de que o computador é um dos grandes obstáculos para que as crianças e os jovens gostem de ler, o que não vem sendo confirmado por estudos nessa temática (PEREIRA, 2006; 2009). Salienta-se, primeiramente, a esse respeito, que as pesquisas sobre redes cognitivas permitem 0 estabelecimento de convergências importantes entre o processo cognitivo de leitura e o sistema que constitui o computador, ambos em rede. Disso decorre principalmente a adequação desse equipamento como caminho para a pedagogia da leitura. Além disso, a dimensão interativa que ele possibilita, movida pela ação desenvolvida pelo aluno e pelo professor/monitor, pois pode tornar o trabalho pedagógico mais produtivo, na medida em que mantém esses usuários interessados no trabalho que é proposto. Revela-se, como decorrência, o fato de que, utilizando-o como ferramenta, o processo de aprendizado se acelera associado ao fato de que o grau de satisfação é elevado, acentuando-se o crescimento da autoestima.

Essas constatações estão provavelmente vinculadas ao processo de interação que se estabelece entre o usuário e a máquina e às associações possíveis entre as redes cognitivas daquele e as redes eletrônicas dessa.

Diante disso, não pode ser negada a existência de um equipamento atraente e que traz em si a possibilidade de constituir-se em elemento instigador do desejo de ler e, o mais importante, orientador do processo de ler (MILLER, 2009; COSCARELLI, 2002).

Do mesmo modo, a folha de papel, que recebe um texto impresso, consiste numa tecnologia não virtual, que por bastante tempo foi única. Hoje, em meio ao virtual, ela continua com seu lugar garantido. A escola, por razões culturais e de infraestrutura, lhe dá um espaço privilegiado. As pesquisas sobre compreensão leitora têm sido predominantes no suporte impresso, do que decorre a existência de maior número de dados nesse formato. 
No estudo aqui exposto, os dois tipos de tecnologias estão presentes na elaboração, aplicação e investigação de atividades pedagógicas com foco em uso de estratégias de leitura, sendo examinada sua produtividade na leitura de textos literários com estrutura narrativa dominante (BAZERMAN, 2009; ADAM, 2008), por estudantes de escola.

Nessa perspectiva o estudo teve como objetivo central verificar a contribuição de oficinas (20h) com materiais com foco em estratégias de leitura (predição, scanning e leitura detalhada) de textos literários constituídos de estruturas narrativas dominantes (conto, crônica e fábula), utilizando tecnologias virtuais e não virtuais, para o uso dessas estratégias por alunos de $9^{\circ}$ ano do EF e de $1^{\circ}$ ano do EM.

Considerando esse objetivo, nortearam o trabalho as seguintes questões de pesquisa: 1) qual a contribuição de oficinas com materiais em tecnologia virtual e tecnologia não virtual, com foco em estratégias de leitura de crônicas, contos e fábulas, para o uso dessas estratégias?; 2) em que medida o uso das estratégias de leitura trabalhadas está associado às tecnologias utilizadas (virtual e não virtual)?; 3) em que medida o uso das estratégias de leitura trabalhadas está associado aos gêneros utilizados (crônica, conto e fábula)?.

Cabe registrar que a escolha desses textos decorreu de estudos anteriores que os apontaram como importantes na formação leitora dos alunos, de observação da frequência nos espaços escolares e de conversas com os professores das turmas que os indicaram como oportunos. Os textos escolhidos foram distribuídos entre os módulos da seguinte forma: módulos 1, 2 e 3 - fábulas; módulos 4, 5 e 6 - crônicas; módulos 7, 8 e 9 - conto.

As atividades de ensino, como já exposto, foram organizadas em nove módulos, todos gerados em tecnologia virtual e em tecnologia não virtual, sendo cada módulo constituído de três partes: parte 1 - atividades de uso da estratégia de predição; parte 2 - atividades de uso da estratégia de scanning; e parte 3 - atividades de uso da estratégia de leitura detalhada. É importante registrar que cada atividade é constituída de uma tarefa de uso da estratégia de leitura em foco.

Para o desenvolvimento das oficinas (20h), os 52 alunos de $1^{\circ}$ ano do EM da escola selecionada, correspondendo a três grupos (turmas), foram distribuídos para trabalho com tecnologia virtual e para trabalho com tecnologia não virtual. Com base nesses critérios, considerando a existência de três turmas, foram indicadas uma, com 20 alunos, para trabalho com tecnologia virtual e duas, somando 32 alunos, para trabalho com tecnologia não virtual. Essas decisões foram tomadas junto com as professoras da escola selecionada, considerando sua proposta pedagógica. Em relação aos alunos do 9a ano do EF, foram indicados 59 alunos de três grupos (turmas), sendo 37 alunos (duas turmas) direcionados para trabalho em ambiente virtual e 22 alunos (uma turma) direcionados para trabalho em ambiente não virtual.

Essas oficinas foram conduzidas por duas professoras da escola (bolsistas AT), por dois graduandos de Letras (bolsistas IC) e por seis estudantes da escola (bolsistas IC Júnior), com a supervisão de uma doutoranda de Letras.

A investigação das contribuições das oficinas foi realizada com base nos pré-testes e nos pós-testes, preenchidos pelos alunos antes e após as oficinas. Foram organizados com apoio nos textos da mesma natureza dos trabalhados nas oficinas, sendo constituídos de tarefas de uso das três estratégias de leitura. Desse modo, em cada teste, foram utilizados três textos (uma fábula, uma crônica e um conto) com três questões por texto, sendo cada uma voltada para uma das estratégias de leitura estabelecidas. Totalizando nove questões, cada instrumento foi organizado com três questões de predição, três questões de scanning e três questões de leitura detalhada.

Os dados coletados foram levantados, tabulados, tratados por um estatístico ${ }^{2}$, organizados em tabelas e analisados. Essas análises possibilitaram a obtenção dos resultados expostos a seguir.

\footnotetext{
${ }^{2}$ Prof. Dr. João Feliz - Faculdade de Matemática da PUCRS.
} 


\section{Resultados}

Os dados apresentados nas Tabelas 1 e 2 decorrem da aplicação dos instrumentos de pesquisa em relação ao uso das estratégias de leitura em situações de pré-teste (tempo 1) e pós-teste (tempo 2) - antes e depois das oficinas, com atividades virtuais e não virtuais de ensino.

Os dados coletados foram organizados de modo a favorecer comparações entre os dois anos de escolaridade e relações com o ambiente tecnológico de aprendizagem e os gêneros textuais utilizados. Após, foram tratados estatisticamente, de modo a verificar médias e a presença de significância nos dados, o que decorre de valor de $\mathrm{P}$ inferior a 0,005 $(P<0,005)$.

A Tabela 1 apresenta os dados dos alunos do $9^{\circ}$ ano e do $1^{\circ}$ ano no uso de estratégias de leitura por gênero textual antes e depois das oficinas realizadas.

Tabela 1 - Uso de estratégias de leitura: tempo, escolaridade e gênero textual.

\begin{tabular}{|c|c|c|c|}
\hline \multicolumn{4}{|c|}{ 9 Ano } \\
\hline Gênero & Tempo & Média & Sig ${ }^{a} /$ tempo \\
\hline \multirow{2}{*}{ Fábula } & 1 & 1,299 & \multirow{2}{*}{, 000} \\
\hline & 2 & 2,534 & \\
\hline \multirow{2}{*}{ Crônica } & 1 & 0,579 & \multirow{2}{*}{, 000} \\
\hline & 2 & 2,638 & \\
\hline \multirow{2}{*}{ Conto } & 1 & 1,316 & \multirow{2}{*}{, 000} \\
\hline & 2 & 2,756 & \\
\hline \multicolumn{4}{|c|}{ 1 Ano } \\
\hline Gênero & Tempo & Média & Sig ${ }^{\text {a }}$ tempo \\
\hline \multirow{2}{*}{ Fábula } & 1 & 1,025 & \multirow{2}{*}{, 000} \\
\hline & 2 & 2,378 & \\
\hline \multirow{2}{*}{ Crônica } & 1 & 0,556 & \multirow{2}{*}{, 000} \\
\hline & 2 & 2,525 & \\
\hline \multirow{2}{*}{ Conto } & 1 & 1,347 & \multirow{2}{*}{, 000} \\
\hline & 2 & 2,775 & \\
\hline
\end{tabular}

Os dados da Tabela 1 correspondem ao desempenho dos grupos de alunos do $9^{\circ}$ ano e do $1^{\circ}$ ano no pré-teste (tempo 1) e no pós-teste (tempo 2) por gênero textual -fábula, crônica e conto. $\mathrm{Na}$ comparação entre pré e pós-teste, os dados revelam ocorrência de médias mais altas no pós-teste em relação ao pré-teste em todos os gêneros e nos dois grupos pesquisados. Essa diferença é estatisticamente significativa, sendo, os valores de $P$, equivalentes à significância dos dados, inferiores a $0,005(\mathrm{P}<0,005)$ nos dois grupos investigados, conforme tratamento estatístico desenvolvido, corroborando, desse modo, os benefícios do material pedagógico utilizado, constituído de estratégias de leitura virtuais e não virtuais.

Observando os dados sob a perspectiva individual dos grupos em cada gênero, os dados do 9 은 ano evidenciam: na fábula - pré-teste 1,299 e pósteste 2,534; na crônica - pré-teste 0,579 e pós-teste 2,638; e no conto - pré-teste 1,316 e pós-teste 2,756 . A observação das diferenças entre as médias, na comparação pré-teste e pós-teste, permite constatar maior crescimento na crônica $(2,059)$, seguida do conto $(1,440)$ e da fábula $(1,235)$. Apesar de não ter alcançado a maior média no pós-teste, a crônica apresenta maior evolução entre os três gêneros contemplados no estudo. Conforme comparação realizada entre os dados anteriores e posteriores às oficinas, a crônica evidencia a menor média no préteste, resultando possivelmente desse fato ser 0 gênero de maior aproveitamento.

Em relação aos resultados do $1^{\circ}$ ano, os dados revelam contribuição dos materiais constituídos de estratégias de leitura virtuais e não virtuais também para esse grupo, sendo as médias registradas no pósteste mais altas em comparação às do pré-teste em todos os gêneros: fábula - pré-teste 1,025 e pós-teste 2,378; crônica - pré-teste 0,556 e pós-teste 2,525; e conto - pré-teste 1,347 e pós-teste 2,775.

Uma análise sob a perspectiva do gênero de maior crescimento nesse grupo indica comportamento semelhante ao observado nos dados do $9^{\circ}$ ano. No que se refere ao ranking de crescimento dos gêneros na relação pré e pós-teste, os dados revelam a crônica $(1,969)$ na primeira posição, seguida do conto $(1,428)$ e da fábula $(1,353)$ na terceira posição. Outra semelhança está no registro da crônica como o gênero com a menor média no pré-teste, elucidando a 
ocorrência de maior produtividade conferida ao gênero crônica também nesse grupo.

Uma análise em relação à variável escolaridade indica o grupo do $1^{\circ}$ ano com médias mais altas no conto (pré e pós-teste) e o grupo do 9a ano com médias mais altas na crônica e na fábula (pré e pós-teste). Em termos de crescimento (pré e pós-teste), os dados mostram o $1^{\circ}$ ano com diferença maior no conto e o $9^{\circ}$ ano com diferenças mais altas na crônica e na fábula. Uma análise sob a perspectiva global dos dados revela que, em termos de valores de crescimento pré/pósteste, $01^{\circ}$ ano apresentam, na totalidade, maior crescimento, embora a diferença seja pequena em relação ao crescimento do $9^{\circ}$ ano.

Os dados expostos na Tabela 2 contemplam o uso da tecnologia virtual e da tecnologia não virtual, oportunizando examinar a sua relação com cada gênero e com a escolaridade.

Tabela 2 - Uso de estratégias de leitura: tecnologia, escolaridade e gênero textual.

\begin{tabular}{|c|c|c|c|}
\hline \multicolumn{4}{|c|}{ 90 Ano } \\
\hline Gênero & Tecnologia & Média & Sig $^{\mathrm{a}}$ \\
\hline \multirow{2}{*}{ Fábula } & 1 & 1,811 & \multirow{2}{*}{0,199} \\
\hline & 2 & 2,023 & \\
\hline \multirow{2}{*}{ Crônica } & 1 & 1,581 & \multirow{2}{*}{0,654} \\
\hline & 2 & 1,636 & \\
\hline \multirow{2}{*}{ Conto } & 1 & 2,095 & \multirow{2}{*}{0,472} \\
\hline & 2 & 1,977 & \\
\hline \multicolumn{4}{|c|}{ 1 Ano } \\
\hline Gênero & Tecnologia & Média & Sig $^{\mathrm{a}}$ \\
\hline \multirow{2}{*}{ Fábula } & 1 & 1,7 & \multirow{2}{*}{0,987} \\
\hline & 2 & 1,703 & \\
\hline \multirow{2}{*}{ Crônica } & 1 & 1,55 & \multirow{2}{*}{0,886} \\
\hline & 2 & 1,531 & \\
\hline \multirow{2}{*}{ Conto } & 1 & 2,075 & \multirow{2}{*}{0,854} \\
\hline & 2 & 2,047 & \\
\hline
\end{tabular}

Os dados da tabela 2 apresentam informações sobre as médias pré/pós-testes, considerando as tecnologias - virtual (1) e não virtual (2) -, os gêneros textuais e a escolaridade.

No grupo do $9^{\circ}$ ano, podem ser observadas as seguintes médias: na fábula - virtual 1,811 e não virtual 2,023; na crônica - virtual 1,581 e não virtual
1,636; e no conto - virtual 2,095 e não virtual 1,977. Os dados evidenciam, na fábula e na crônica, tendência favorável ao ambiente não virtual e, no conto, tendência a favor do ambiente virtual. Apesar de os dados do $9^{\circ}$ ano indicarem tendência favorável predominantemente ao ambiente não virtual, o tratamento estatístico revela valores de $\mathrm{P}$ maiores que 0,005 ( $P=0,199$ na fábula; $P=0,654$ na crônica; e $P$ = 0,472 no conto), não sendo possível, desse modo, constatar diferença estatisticamente significativa entre as tecnologias virtual e não virtual.

Desse modo, uma análise sob a perspectiva global, considerando os três gêneros, por ambiente, ratifica, para o 9a ano, a tendência favorável da tecnologia não virtual em relação à virtual.

No grupo do $1^{\circ}$ ano, as médias são: na fábula virtual 1,700 e não virtual 1,703; na crônica - virtual 1,550 e não virtual 1,531; e no conto - virtual 2,075 e não virtual 2,047. Esses dados são favoráveis ao ambiente virtual, na medida em que em dois gêneros na crônica e no conto - entre os três contemplados, as médias são mais altas quando há uso da tecnologia virtual. Quanto à fábula, cabe registrar vantagem pequena $(0,003)$ a favor do ambiente não virtual em comparação ao ambiente virtual. Essas diferenças são, então, favoráveis ao ambiente virtual, embora não sejam estatisticamente significativas, de acordo com o tratamento estatístico desenvolvido, pois os valores de $P$ são maiores do que 0,005 na fábula $(P=0,987)$, na crônica $(P=0,886)$, e no conto $(P=0,854)$.

Esses dados comparativos apontam as seguintes tendências: associação favorável do ambiente não virtual ao $9^{\circ}$ ano e ao trabalho com fábula e crônica nesse nível de escolaridade; associação favorável do ambiente virtual ao $1^{\circ}$ ano no trabalho com crônica e conto.

Os resultados alcançados com base nos dados coletados e até aqui expostos dão condições para responder às questões norteadoras da pesquisa, refletindo sobre eles e fazendo encaminhamentos para a organização do ensino da leitura e para o desenvolvimento de pesquisas nessa mesma direção. 


\section{Conclusão}

Os resultados obtidos dão suporte para responder às questões de pesquisa apresentadas inicialmente no presente artigo.

No que se refere à questão de pesquisa 1 (Qual a contribuição de oficinas com materiais em tecnologia virtual e tecnologia não virtual, com foco em estratégias de leitura de crônicas, contos e fábulas para o uso dessas estratégias?), os resultados mostram desempenhos superiores no pós-teste em relação ao pré-teste, em todos os gêneros, nos dois ambientes de aprendizado propostos - virtual e não virtual -, e nos dois grupos de sujeitos, indicando a contribuição do material pedagógico programado e aplicado nas oficinas com os alunos dos dois grupos em investigação - 9ำ e 1ำ ano. Essa diferença na relação pré e pós-teste é estatisticamente significativa nos três gêneros contemplados na pesquisa, nos dois ambientes propostos e nos dois anos escolares em análise, apresentando valores de P inferiores a 0,005. Desse modo, os dados obtidos respondem à questão de pesquisa 1.

Quanto à questão de pesquisa 2 (Em que medida o uso das estratégias de leitura trabalhadas está associado às tecnologias utilizadas?), os dados diferem sob a perspectiva da escolaridade. No $9^{\circ}$ ano, há tendência favorável ao uso da tecnologia não virtual, em comparação à virtual, enquanto, no $1^{\circ}$ ano, os resultados são favoráveis à tecnologia virtual em relação à não virtual. Os resultados evidenciam existência de diferenças nos valores de médias, embora não sejam estatisticamente significativas, assim respondendo à segunda questão de pesquisa.

Em relação à questão de pesquisa $3(\mathrm{Em}$ que medida o uso das estratégias de leitura trabalhadas está associado aos gêneros utilizados?), os resultados revelam, nos dois grupos em análise, o mesmo comportamento dos gêneros em relação ao crescimento. Em um ranking de evolução, a crônica se destaca na primeira posição, registrando o maior índice de crescimento entre os três gêneros contemplados, sendo seguida do conto (segundo lugar) e da fábula (terceira posição).
As respostas às questões de pesquisa apresentadas orientam para reflexões sobre o trabalho desenvolvido e apresentam encaminhamentos para o ensino e a pesquisa da leitura.

Inicialmente, cabe associar o benefício dos materiais elaborados ao conteúdo das atividades - uso de estratégias de leitura. O crescimento obtido na relação pré e pós-teste pode ser considerado produtivo, tendo para isso colaborado a metodologia de trabalho direcionada a esse foco, importante alicerce para o manejo de textos com vistas à sua compreensão. Essa condição deve ter contribuído para a evolução significativa dos alunos nos dois grupos.

Em relação ao uso da tecnologia, a tendência favorável do $9^{\circ}$ ano para o ambiente não virtual e do $1^{\circ}$ ano para o ambiente virtual pode estar relacionada a uma dupla situação vivenciada pelos estudantes - 0 convívio frequente com o virtual no cotidiano, gerador de grande interesse, e o convívio predominante na escola com o não virtual, gerador de hábitos nesse suporte. Os resultados obtidos parecem apontar para o uso de propostas metodológicas de ensino que considerem ao mesmo tempo as condições que marcam o cotidiano dos estudantes e as que caracterizam a trajetória histórica das práticas escolares em que estão inseridos. $\mathrm{Na}$ busca de caminhos produtivos para o ensino da leitura, parece ser importante o uso de tecnologias virtuais e não virtuais, preferencialmente em condição complementar.

Em relação aos gêneros, os resultados mostram uma maior afinidade dos alunos com a crônica. A fábula, por sua vez, constitui o gênero de menor afinidade. Esses dados evidenciam o tipo de condução desenvolvida pela escola, indicando a carência de um trabalho contínuo com suporte em gêneros previamente estabelecidos e objetivos bem definidos. Disso decorre a natureza da relação entre gênero textual e ano de escolaridade apontada pela pesquisa a partir do ranking de crescimento sustentado (crônica, conto e fábula) nos dois anos em análise - 9ํano e $1^{\circ}$ ano. Esse resultado levanta hipóteses sobre o trabalho 
com gêneros desenvolvido pela escola, em que a diferença entre o $9^{\circ}$ ano e o $1^{\circ}$ ano é discreta.

No que se refere à escolaridade dos sujeitos da pesquisa, os resultados mostram um crescimento mais favorável no $1^{\circ}$ ano em relação ao 90 ano. Cabe salientar o fato de que esse crescimento é muito pequeno considerando os cálculos de médias realizados. Fica então o questionamento sobre as razões de ocorrência desses resultados, cabendo levantar hipóteses sobre as características do trabalho escolar e das orientações oficiais, ambas na verdade interligadas.

Os resultados da pesquisa aqui relatada, como os de tantas outras sobre leitura, podem contribuir para compreensão dos frágeis desempenhos dos estudantes nas avaliações oficiais, processo importante para a construção de rumos para o ensino no EF e no EM, de modo a se configurarem efetivamente como norteadores na seleção e organização dos conteúdos e procedimentos em cada ano escolar e a garantirem a evolução dos estudantes a cada ano da escolaridade.

Podem também contribuir para o reconhecimento da relevância de pesquisas voltadas para o ensino a serem realizadas, como as que envolvam geração e testagem de materiais didáticos, as que investiguem estratégias de leitura de diferentes naturezas, as que examinem tecnologias diversas em condição complementar, enfim as que tenham a densidade teórica necessária para a constituição produtiva de situações de ensino e assim contribuam para a definição de orientações precisas para o trabalho escolar e para a solução de problemas de leitura identificados entre os estudantes de nível fundamental e nível médio.

\section{Referências}

ADAM, Jean-Michel. A Linguística: introdução à análise textual dos discursos. 2. ed. São Paulo: Cortez, 2008. 368 p.

BAZERMAN, Charles. Gêneros textuais, tipificação e interação. 3. ed. São Paulo: Cortez, 2009. 165 p.

COSCARELLI, Carla Vianna. Novas tecnologias, novos textos, novas formas de pensar. Belo Horizonte: Autêntica, 2002.

GOMBERT, Jean Émile. Metalinguistic development. Chicago: The University of Chicago Press, 1992. $238 \mathrm{p}$.

GOODMAN, K. S. Reading: A psycholinguistic guessing game. Journal of the Reading Specialist, v. 6 , Issue 4, p. 126-135, 1967.

GOODMAN, K. S. Unidade na leitura - um modelo psicolinguístico transacional. Letras de Hoje, Porto Alegre: EDIPUCRS, n. 86, p. 9-43, dez, 1991.

KATO, Mary Aizawa. O aprendizado da leitura. São Paulo: Martins Fontes, 1987.

KLEIMAN, Angela. Texto e leitor: aspectos cognitivos da leitura. Campinas: Pontes, 1989.

LEFFA, Vilson. Aspectos da leitura: uma perspectiva psicolinguística. Porto Alegre: Sagra, 1996.

MILLER, Carolyn R. Estudos sobre gênero textual, agência e tecnologia. Recife: EUUFPE, 2009.

PEREIRA, Vera Wannmacher. Computer-Based Learning of Reading and Writing in Elementary School. In: CESTARI, Maria Luiza; MAAGERO, Eva; TONNESSEN, Elise Seip. (Orgs.). Networking Cultures. 1. ed. Kristiansand: Portal Books, 2006. P. 107-117.

PEREIRA, Vera Wannmacher. Estratégias de leitura virtuais e não virtuais no ensino fundamental. In: VI Congresso da Abralin, 2009, João Pessoa. Anais do VI Congresso da Abralin, v.2, p. 10-22. Disponível em: http://www.abralin.org/. Acesso em 03.06.2009. Apresentação em CD.

PEREIRA, Vera Wannmacher. Compreensão leitora de alunos do Ensino Médio. Revista Virtual de Estudos da Linguagem, v. 6, p. 1-15, 2008.

PEREIRA, Vera Wannmacher; PICCINI, Maurício. Preditibilidade: um estudo fundado pela Psicolingüística e pela Informática. In: Letras de Hoje, n.144. Porto Alegre: EDIPUCRS, jun. 2006. 
SCLIAR-CABRAL, Leonor. Processamento bottom-up na leitura. Veredas on-line-Psicolinguística-PPG Linguística/UFJF - Juiz de Fora, p. 24-33, 2008. Disponível em: http://www.ufjf.br/revistaveredas/files/2009/12/artig o02.pdf. Acesso em: 22 mai. 2011.

SCLIAR-CABRAL, Leonor. (2009). Processamento da leitura: recentes avanços das neurociências. In:
PEREIRA, Vera Wannmacher; COSTA, Jorge Campos da (orgs.). Linguagem e cognição: relações interdisciplinares. Porto Alegre: EDIPUCRS, 2009, p. 49-60.

SMITH, Frank. Compreendendo a leitura. Porto Alegre: Artes Médicas, 2003.

\section{COMO CITAR ESSE ARTIGO}

WANNMACHER PEREIRA, Vera Wannmacher; VARGAS DOS SANTOS, Thais Vargas. Uso de estratégias de leitura em tecnologia virtual e tecnologia não virtual: um estudo com alunos do 9ำ ano do Ensino Fundamental e do $1^{\circ}$ ano do Ensino Médio. Signo, Santa Cruz do Sul, v. 41, n. 71, set. 2016. ISSN 1982-2014. Disponível em: $<$ https://online.unisc.br/seer/index.php/signo/article/view/7082>. Acesso em: doi: http://dx.doi.org/10.17058/signo.v41i71.7082. 